\title{
First report of tomato leaf curl Palampur virus infecting muskmelon in India
}

\author{
Manmohan Dhkal $^{1}$ (D) $\cdot$ Abhishek Sharma ${ }^{2} \cdot$ Gurpreet Kaur $^{2}$ \\ Received: 9 July 2020 / Accepted: 26 August 2020 / Published online: 31 August 2020 \\ (C) Società Italiana di Patologia Vegetale (S.I.Pa.V.) 2020
}

Keywords Muskmelon · Tomato leaf curl Palampur virus · Yellows and leaf curl · India

During February-July 2016-2018, severe symptoms of virus(es) and infestation of whitefly (Bemisia tabaci) were observed on muskmelon (Cucumis melo) crop in Ludhiana, Kapurthala and Jalandhar district of Punjab state. Approximately 20\% of the plants exhibited severe yellowing and curling of leaves along with necrotic streaks symptoms on the fruits across a 25 ha area surveyed. These symptoms resembled to the recently described infection of whitefly transmitted begomovirus on melon (Trisciuzzi et al. 2018). DNA of 40 symptomatic samples was tested by PCR with begomovirus primer pair PALIc and PARIv (Rojas et al. 1993), yielding an approximately 1280 bp DNA product in size in all the samples. To further identify the associated begomovirus species, three PCR amplicons were cloned in pTZ57R/T vector and sequenced. BLASTn analysis of the sequences (MH823545, MH837670 and MH844512) showed 97.3\%-99.8\% nucleotide identity with tomato leaf curl Palampur virus (ToLCPaLV) accessions GU253914, HG934859, HQ848383, KC456161 and KY564205. The coat protein showed $100 \%$ amino acid identity with ToLCPaLV isolate Mahuadhab from bitter cucumber in Uttar Pradesh, India. Primer pairs specific for the detection of major tomato leaf curl begomoviruses viz. tomato leaf curl New Delhi virus (ToLCNDV), tomato leaf curl Gujarat virus (ToLCGV), tomato leaf curl Karnataka virus (ToLCKV), tomato leaf curl Bangalore virus (ToLCBV) (Reddy et al. 2005) and tomato leaf curl Palampur virus (ToLCPaLV) (Personal communication Yogesh Kumar, IHBT, Palampur, Himachal Pradesh, India) were tested in PCR. A specific DNA product

Manmohan Dhkal

manmohan90@pau.edu

1 Department of Plant Pathology, Punjab Agricultural University, Ludhiana 141004, India

2 Department of Vegetable Science, Punjab Agricultural University, Ludhiana 141004, India of 875 bp was only obtained with primer pair specific to ToLCPaLV in the 40 samples tested. To the best of our knowledge, this is the first report of infection of ToLCPaLV from muskmelon in India.

Acknowledgements Authors are thankful to DST, Govt. of India for INSPIRE fellowship to $1^{\text {st }}$ author and facilities created under PURSE and FIST programme.

\section{Compliance with ethical standards}

Conflict of interest Authors have no conflict of interest.

Human and animal rights and informed consent This article does not contain any studies with human participants or animals performed by any of the authors.

\section{References}

Reddy RVC, Colvin J, Muniyappa V, Seal S (2005) Diversity and distribution of begomoviruses infecting tomato in India. Arch Virol 150: 845-867

Rojas MR, Gilbertson RL, Russell DR, Maxwell DP (1993) Use of degenerate primers in the polymerase chain reaction to detect whitefly transmitted geminiviruses. Plant Dis 77:340-347

Trisciuzzi N, Silletti MR, Gallitelli D, Spano R (2018) First detection of tomato leaf curl New Delhi virus in melon and zucchini squash in southern Italy. J Plant Pathol 100:149

Publisher's note Springer Nature remains neutral with regard to jurisdictional claims in published maps and institutional affiliations. 